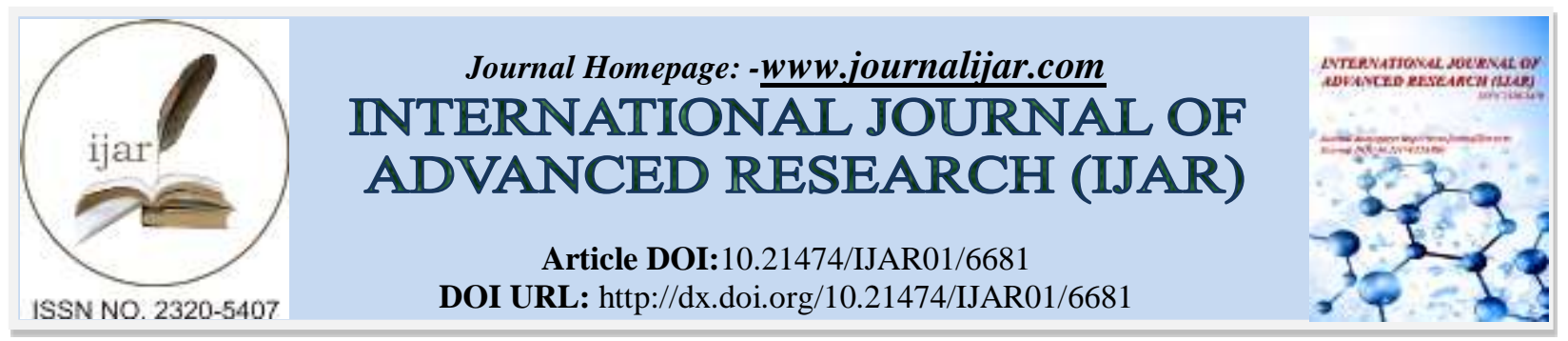

RESEARCH ARTICLE

\title{
HUMAN-COMPUTER INTERACTION ENHANCEMENT IN LEARNING AND TEACHING IN SCHOOLS.
}

\author{
Douglas Omwenga Nyabuga and Erick Isaboke Nyasani. \\ Mount Kenya University - Kigali (Rwanda).
}

\section{Manuscript Info}

Manuscript History

Received: 06 January 2018

Final Accepted: 08 February 2018

Published: March 2018

Keywords:-

Human-Computer Interaction;

Enhancement; Information Systems;

Learning and Teaching.

\begin{abstract}
Human-computer interaction has a significant contribution in the designing and developing computer systems that have a diversity of different features and rationale in the world today. The designing of the right user-centred interface is a big challenge in systems development because a wrongly designed interface will result in resistance from different levels of users. On the other hand, the right user interface motivates the learners as well as the teachers to adopt the use of information system in learning and teaching. This study focuses on establishing how the human-computer interaction heightens the learning and teaching in schools; establishing the challenges facing learners and instructors of human-computer interaction, as well as investigate the influence of the user-centered approach in the adoption of information systems in learning and teaching and finally make a recommendation on the fundamentals for successful enactment of an information technology program in our schools.
\end{abstract}

Copy Right, IJAR, 2018,. All rights reserved.

\section{Introduction:-}

The subject Human-computer interaction deals with the planning, assessment, and execution of collaborative computer devices for social usage, the functioning, operation and the interaction that involves the applications of it [1]. It can also mean the designing or building computer systems that help users or persons to perform various tasks efficiently, effectively and safely. The designing of the computer system involves technology and the productivity, the social connectedness, priority on the human dimension of computer interaction it's all about safety of it [2].

Gathering, storage, and imminent usage of information or data by the logical computer is referred as learning. In cases where the practices are not correctly followed and executed, the students will not be able to achieve the intended knowledge and information, and if they do, then it will be very difficult to remember it in the future or the knowledge will not be applied at all [3].

There is a rich potentiality in information technology that can be integrated into learning and teaching but in remains unrealized. The integration of this IT can be well-defined and distinguished of what the teacher has access to, the time s/he had time to study about or finds.

Applicable for use; also what the students have access to, are conversant with, and ready to use. Above all these, information technology often plays an aide part to additional outdated modalities for learning and teaching; that includes lectures/talks, workshops, library, textbooks, lessons and practical's or seminars. To successfully modify 
or change will involve both the use of outdated or old and information systems tools and approaches, developing on and encompassing old common methods of learning and teaching. Execution of the suitable tools and methods requires a keen evaluation of the learning and teaching activities and the appropriate method to that activity or task. Most of the schools assume the traditional methodologies of learning and teaching, i.e. the use of lecture halls and giving out the lecture. Assuredly, certain methods of learning and teaching can be encouraged most by the teacher and the learner. Interactions, for example, that involves a section of a play and of uncertainty that makes a presentation more interactive and involving, which gives students an experience of visualization of the content and be able to grasp the knowledge through the use of scientific techniques and metrics. This technique can lead to new discoveries that have not been published yet. Nonetheless, most of the methods used can be well implemented, using the old fashion of prints, since the student (s) needs of the print as a reference while learning the new models. The human-computer interaction is more suitable principally for learning and teaching activities that require huge quantities of variations that interrelate in multifaceted means and can only be understood through conducting experiments. A face to face and self-learning methodology can work very well for fact-finding learning, but not adequate for the study that needs accurate results in detail and realistic knowledge.

Worldwide Web, the most current model that is being used for learning and teaching incorporates much more information and different technologies that enable the teachers and learners to access and retrieve more information from what is available on the web pages more than what is needful at the moment and what they should use the information for.

There are many reasons why many use the Internet for learning and teaching, some of the reasons are: first, the users tend to rely on the technological abilities of the Internet web page instructional layout and functionalities; second, the wireless networks that entices to post-modernization; third, the theoretical validations that have appealed to rationalize the Web contents; fourth, these technologies are formed on and build on and replicate a reflect a type of simple positivity about technology, specifically the new technologies, and their responsibility for learning and teaching in schools. What is lacking in the simple positivity about technology and its web pages is what appropriate or suitable use of all these technologies is. Relatively, many users, i.e. the learners and teachers assume its suitability but little has been done to address the issues of its suitability. The increasing demand by students for enhanced and suitability, inexpensive and the direct applications of the information in their works are fundamentally changing learning in schools. The prospect of learning methods is turning into a technological, networked, information based and knowledge based.

The collaboration of both students, and teachers in building up and segmentation of knowledge, designing of new techniques of learning and teaching that caters for the needs and dreams of students at any place, anytime on any electronic device can be attained through the use motion videos [4]. The information technology has drastically changed the way students and teachers live and even communicate and how they learn; the current advancement in information technology with the use of different technologies such as smartphones, personal computers, notebooks or laptops, the Internet, cell-phones, tablets and internet of things, are becoming part of our daily life and people cannot live without them in this modern world of information technology. Almost everyone has become addictive to these technologies and any change directly affects the society and the operations.

Technology advancement has influenced users' interaction approaches with technology. In this digital or information technology age whereby embracing and using information systems such as the Internet, hardware, software, data/information, telecommunication, networking, people in processing and disseminating of information in various sectors of the development of the country, e.g. education, transportation, health, banking, infrastructure etc., is very important. In order for all these systems to function effectively and efficiently there must be accessibility and availability of the information systems that will enable human-computer interaction enhancement of learning and instruction in institutions; without which they will be very challenging and difficult to execute the process. Not only the lack of information systems hinders the enhancement of HCI but also the user-centred design of them determines the implementation and interaction of the computing systems by the learners and teachers, due to this the researcher wants to establish the role human-computer interaction plays in the boosting instructing and education in institutions. Figure 1, below is a structure of the elements of information systems that enables effective enhancement of $\mathrm{HCI}$ in learning and teaching; 


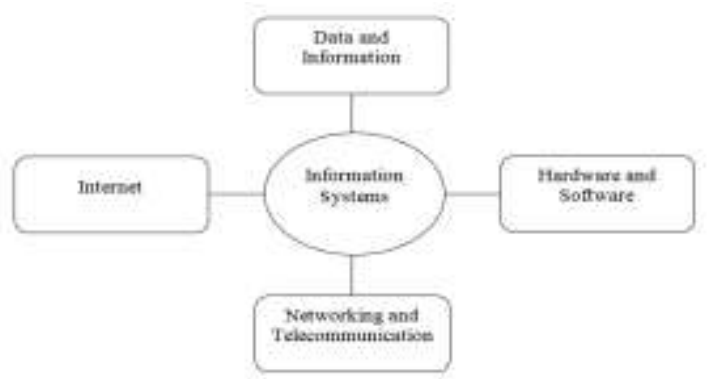

Fig. 1:- Structure for the elements of Information System

The other sections of this study is systematized as follows; Section two looks at the ways in which human-computer interaction enhances learning and teaching in schools, the challenges the students and teachers are facing in the human-computer interaction enhancement; Section three deals with the user-centredness design and its influence; Section four entails the conclusions and recommendations and Section five is about the acknowledgements and references.

\section{Related Work:-}

The ways in which human-computer interaction enhances learning and teaching in schools:-

There are several methods in which the appropriate incorporation of information systems in learning and teaching contributes the excellence in content delivery in the classrooms. Computer systems are a treasured tool that can enhance and support learning and teaching when used effectively for the rightful purpose. They can help the students to easily assimilate knowledge during their learning processes. This can be achieved through the integration of the computer based systems with practicing programs, learning tutorials, technology-enabled systems with integrated learning systems, Internet-based learning with valid content such as multimedia information and software that will enable students to learn and grasp the knowledge in a practical way.

Computer networking, adoption of this technology to enable the linking of computer systems within the communication channels that makes it easy access to information and creates opportunities for students, teachers and any other person to learn effectively. For the schools that cannot be able to afford the networking and installation, should negotiate with the hardware and software vendors to help in the accessibility and usage of this information system.

Internet is an asset of resources from which teachers and students can learn and it's very significant in all levels of learning in schools. Students as well teachers can use the Internet for communication, i.e., sending of emails, room chats to exchange ideas, brainstorm and come up with solutions to problem-solving scenarios, do some scientific research both locally and globally.

The adoption of the computers in instructions and education depends entirely on both the teachers' and the students' skills and knowledge in the learning processes.

Students learn faster when they are enthusiastically involved in the usage of the technologies and when they are in control of the computer systems themselves; they discover a lot (Harris, 1991). The students and the teachers should both be responsible for making sure that the constant progress in the learning and embracing of technology [5], [6], [7] in which [8] it explains on the learner can learn individually, i.e. what the student can be able to master by himself or herself and what can be achieved with the help of the expert or an instructor.

\section{Resistance of schools to change to technology-based learning and teaching:-}

In most schools a few of the teachers uses computer systems in teaching, the following are assumed to be the reasons why it's taking longer to adapt the use of computer systems in teaching in schools; first, teachers might not be ready to adopt information technology in delivering the content in the classrooms; second, sometimes the main obstacle to effective technology adoption might be a lack of access to the computer systems; third, teachers lack enough time to appropriately integrate technology into the lessons and learning; fourth, the income level of the teachers do not support them to integrate the technology standards that they want to use in the classrooms; fifth, most of the computer systems that are used some of them might not be able to run sophisticated learning software or 
programs because they might not be powerful enough to support the programs, they might lack the graphics, animation, or the audio/video interactivity due to it's outdated; sixth, the class demands are too high e.g., the class size, high demanding teaching schedules or timetables, administration responsibilities apart from teaching, etc., makes it very difficult for the teachers to have enough time to learn on how to incorporate computer-based technologies in instructing and education; finally, some schools might not be able to purchase enough computer systems due its setup, i.e., sometimes it becomes too expensive for the schools to do the maintenance of the computers and even replacing the old ones [9].

\section{Teachers are more the same like other people who are prone to change:-}

Like any other person, teachers have not been left out to resist changes in technology and this makes it very hard to achieve the human-computer interaction enhancement in learning and teaching. The reasons can be as follows: people are naturally prone to changes which make them think that the automation of the systems will lead to loss of positions or jobs, some are ignorant of the potentiality of computer systems in carrying out various activities, some do not want to learn new technologies, they want to remain in the old fashioned ways of doing out things and sometimes they don't want to give-up the acquired skills or knowledge and advance, all these makes them to resist any technological changes that come across [10], [11].

Schools should design timetables that are flexible to allow students to work together through interaction with computer systems in doing the research, classwork, analysis of data and this will enable the integration of computer technology in different modalities of learning and teaching [12], [13], [14].

The challenges that are encountered by teachers and students:-

In this time of information technology, it's indeed very challenging to totally depend on the educational system to produce technological students; students are able to have access to computer systems, digital devices and advance in learning at the earliest age even before they join the schools. They only use information technology or information systems to solve problems and decision-making to a more sophisticated level even more than their parents and teachers.

The modern students at their young age are more innovative, creative and effective users of information technology tools such as word processors, computer graphics software such as core draw, Photoshop, spreadsheet, presentation and even database software. They also use the email, social networks such as Facebook, instant messaging, Skype, IMO, WeChat, WhatsApp etc., as shown in fig. 2 below; communicating in writing comprehensively more than their adults. Through this interaction with technology right from home, it makes them more advanced even more than their teachers. It causes a big challenge for the students to follow the lesson and concentrate if the information systems are not integrated effectively into the learning and teaching at schools.

Students from developed countries where they have access to information technology like wireless gadgets for communication with $\mathrm{WiFi}$ Internet connectivity everywhere it gives them opportunities to access online contents anytime which they might require. In all these scenarios, it's mandatory that the teachers should be much advanced to embrace the advancement in information technology and internet of things in their teaching in this modern world of technology to make the class more interactive and interesting.

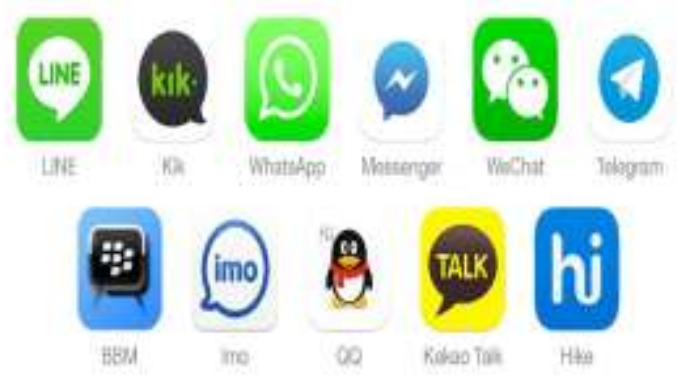

Fig. 2:- Social Networking Applications 


\section{User-Centredness Design And Its Influence:- User-centred design of HCI:-}

The enhancement of human-computer interaction in learning and teaching in our schools depends entirely on the user-centred design of the human-computer interaction itself. How users, i.e., teachers and students and other users access the functionality of the already existing information communication technology; how they interact with the available information systems must support the possible methodologies of teaching and learning processes. Usually, the human-computer interaction is influenced or motivated by the following features: first, the input devices, the hardware that determines what data is transmitted between man and the machine and the way in which the information will be transmitted.

Actions such as mouse movement by the users of interfaces sends a signal to the computer systems which enables the signal that comparatively synchronizes the mouse movements e.g., mouse click, drag etc. the development of a software applications determines the communication between the hardware and the software, and the interpretation of the data e.g., a click from the mouse which represents relative coordinates. For example, incoming signals from mouse movements represents comparative synchronizes that are generally mapped to absolute pointer movements on the screen and as such visualized to the user.

With the old-fashioned human-computer interaction models, e.g., the personal desktop with input devices such the USB keyboard and mouse that are designed classically unlikely, the designs they are not well suited for the tasks appearing in the teaching classroom(s) thus, forcing the instructors to modify and adapt their teaching methods to the used equipment [15]

Implementing a user-friendly human-computer interaction is a way of inventing systems that stimulate helpful and constructive reactions from the implementers e.g., easiness, comfortability, and appreciating. Issues such as user frustration, confusing characters and signs, disturbs the users [16]. Sensational effects, devotion adjustment, and the way these sensations are inclined during human-computer interactions (HCI) leads to biased judgment and inspiration behavior [17].

Frequently, the human-computer interaction is dedicated on the frontend applications; thus, forgetting that the ethics of good interface scheme is also implemented in various circumstances, e.g., in the creation of an online site, cellphones, or computer system. An inclusive enterprise is influenced by having knowledge of the people's perceptions. HCI can be used as a quantifier of the usefulness, productivity, and contentment with which specified users can accomplish defined objectives in a specific setting or platform. Considerations of these ethics makes it probable to design and build interfaces that enables the users to achieve their objectives with practical and significant results that are not subjective.

The response of the human-computer interaction is very indispensable in a functional and interactive interface. There are some interactive principles that are not avoidable, namely; visibility, which deals with the clarity of functions of the different controls which thus leads to easy translation of objectives into actions; affordance that deals with how the device is implemented, for example, the button on the device is supposed to be pushed or pressed, the user should have the operation knowledge by looking at the buttons, and response that deals when a control has been used, this relates to the response that the user receives of the accomplished action, e.g., system sound, underlining, and simulation [18].

A fruitful interaction happens when the user comprehends the limitations of the input devices and already knows how to operate them. These guidelines are well learned and relies on how to fit the computer systems sustains its methods of interaction that are used for many activities or jobs. These interactions are inappropriately habitually visionless in the environment in which they are. This means that beyond the given limitations the input devices or interfaces are not useful at all, e.g., when a presenter gives an oral presentation using computer-based slide presentations, the mouse click indicates when the next slide is. This can be very challenging in cases where the presenter or the teacher walks around the classroom from one point to another, because the limitation of the normal mouse is that it's just connected a computer system and the user move along with it, and being a single interaction technique of input device it limits the user depending on the job to be carried out.

Computer systems should be developed that allow dynamic interactions depending on the operation, environment, and platform that the user is engaged in. The computer system should sense the environment and the user as well 
and picks the best interaction technique that allows the user to comfortably execute his/her tasks without any hindrance. By engaging the computer system and sharing out some burdens it will create a mutual interaction between the computer system and human being and thus becomes human-computer interaction.

For this kind of interactions to happen, the computer systems must be in a position to learn about what the user is doing and what the objectives of those operations might be. With the standard or the normal computer systems, the user only gives the computer systems instructions and the computer system executes the tasks according to those instructions. With the artificial intelligence, the computer system should be able to learn from the user and find out what they are thinking to do next or what they are doing. If there is something that the user is intending to do, the computer system should automatically do it for him/her.

\section{Why User interfaces Are Important:-}

With the advancement in information technology, the users will be very comfortable and happy to have a digital device with ease of use interfaces which is a major influence or determinant in decision making when it comes to choosing which digital device to purchase.

The developers must consider the usability of the computer-based system as an essential feature in human-computer interaction. The users expect to sit down and use the software without any difficulty or frustrations. It should enable the users to easily accomplish whatever tasks or problems they are handling, without which there will be no interactions and usage of the computer systems. No teacher or student wants to spend a lot of time trying to figure out what exactly is all about the software. The usability of the system should be effective and efficient in job delivery.

The key feature of the user-centred system design should mainly focus on the people or users that will be daily using the computer system. The developers must have the users in mind when they are developing the computer system. They should be a user-oriented type of computer systems with simple models that will enable the user to achieve his/her goals easily.

The usability requirements of the computer systems it must be user-friendly systems that are easy to use, accessible, understandable, clear, available and ready.

The usability measures of the computer systems should have the target audience that has to involve some factors such as the time the users will take to learn; the performance speed on specific tasks; a number of errors and the kind of errors they commit when executing the tasks, thus, will help in establishing the human-computer interactions.

The universal usability of the computer systems should accommodate different groups of people e.g., people with disabilities, the inventers must consider these people; this reduces the costs due to early planning rather than late implementation, the infirmities can be vision problem, noise problem, etc.; old users, this includes elderly people or users, designers must have them in mind when designing the development of computer systems that will make these users easily adapt to the color, sound, brightness, font size etc., adjusted to accommodate them; the designers must consider the children when making the design, the computer systems should not be hard to be used by the teenagers because it is at this age that the young people discover the operations of the computer systems; the designing the computer systems must accommodate the diversity of the hardware, the display technology should be able to run large to small, high to low resolutions, the network interface cards that support high and low bandwidths, i.e., Internet interactions; the computer system should enable the users with little technical knowledge or occasional users to use the computer system comfortably with any complexity; the software should be well designed to enhance the learning and teaching and duplicate the teachers' excellence, the most used software such as word processors, database management, spreadsheets, statistical software, multimedia software, content access software, e.g., browsers (Mozilla Firefox, etc.), desktop publishers, presentation software etc., all these types of software should make the process of learning and teach manageable and effective.

\section{Design Complexity of user-interfaces:-}

Even though the advantages of usability concerns are defined, there is no one considers that this brings a solution to the challenges of designing interfaces that are user-centred and friendly. Nonetheless, there are remarkably few considerations why the designing of the user interfaces is very challenging; 
A little knowledge about the jobs to be carried out and the skills of users; designers have a big challenge and difficult times to know about the users they are designing the interfaces. This can be achieved through task analysis. The user feedback on the interaction of software is to help the designers acquire more knowledge on the support of the software to help them build up successive computer systems [19].

Development of the user interface requires a deeper knowledge of the interface users rather than the design of the functionality because the interfaces must be in line with the skills, expertise, anticipations and the wishes of the anticipated users. The human-computer interaction can able to address the issue to accommodate everyone. Although, the designers might not fully address the needs of every user.

In cases of programmers, it's very rare, they think like end-users [20], it's very hard for both programmers and designers to recall of what they were not aware of. In some instances, it's not easy for people to remember learning and trainee times [21]. Therefore, they cannot expect the response to learning and misjudge what the learners or trainees really know.

The diversity of different features and rationale:-

Almost all designs comprise of adjustments, but the user-interface design comprises much more adjustments to suite into various disciplines of interactions. The user-interface is comprised of the following requirements:

\section{Standards:-}

The user-interface must meet the required standards regarding the interface procedures or guidelines. Various companies do observe different standards when designing their interfaces. To meet all the required standards for user-interface design the designers must revisit the previous versions of the invention and design a user-interface that aligns with the old one.

\section{Computer graphics design:-}

Graphic design is one the features that are very crucial in user-interface design which includes the layout of the computer system, the different application modes such as basic, advanced, and wizard, icons design, the font sizes, language and even the screen resolutions, all these must be achieved by the designers to make the user-interface interactive.

\section{The notifications, messages, documentation and help features:-}

The help, notification features have a greater impact on the quality of usability of the computer system comparing to user-interface elegance [22]. Hence, it's very important to involve the technical authors during the designing the user-interface.

\section{Globalization:-}

The computer systems are universal devices with a diversity of different language speakers, designing of the userinterface that accommodates every language is a challenging task comparing to merely translate the text characters. The different time zones, date, new input techniques, new icons and different color patterns must be considered [23].

\section{Performance:-}

Commonly no one would like to use an interface that is too slow to execute the instructions. That's why there have been several changes of Windows to address the issue of performance and user-friendliness. The user-interface designers must continually balance what is appropriate with what will keep up with the input devices such as the mouse or keyboard [24].

\section{Conclusions And Recommendations:-}

Fundamentals for successful enactment of a technology program: For the successful enactment of human-computer interaction in enhancing learning and teaching in schools; first, the leadership has to be committed and supportive, both the learners and teachers must accept the technological changes and adopt to them without resistance, schools must be ready to invest in information technology and train the teachers with new technological skills and they must be ready to integrate it in teaching otherwise they will be marginalized, schools must be in a position to adapt quickly to new technological changes and keep updated, technical support should be given out as demand arises, the parents and students must also be part of the evolution process of information technology to be able to interact 
positively with computer systems and all users must know that information system is for everyone and it requires continuous learning and it's unavoidable because the world is turning into Internet of things.

Creativity is a discerning of new things and innovating is performing new things; a good number of students as well teachers have very good ideas that change the way the school functions, but very few individuals are ready to do what is obligatory to implement their ideas. These ideas when implemented they become productive otherwise they become useless, so both learners and teachers must embrace creativity and innovation in information technology.

\section{References:-}

1. Hewett T.T., Baecker. R, Card. S, Carey. L, Gasen. J, Mantei. M, Perlman. G, Strong. G \& Verplank. W. (2004, June 03). ACM SIGCHI curricula for human-computer interaction . Retrieved from Association for Computing Machinery, Inc: http://www.sigchi.org/cdg/cdg2.htlm

2. Preece, J. (1994). Human-computer interaction. Addison - Wesley: Harlow - UK.

3. Dror, I. (2008). The good, the bad, and the ugly Pragmatics \& Cognition. Technology enhanced learning, 16(2), 215-223.

4. Halkett, R. (2010, December 14). The learning society. San Jose, CA . Retrieved from Cisco Systems: http://www.cisco.com

5. Marilyn Leask, Norbert Pachler. (1999). Learning to Teach Using ICT in the Secondary School. Psychology Press.

6. Dana S. Dunn, Janie H. Wilson, James Freeman, Jeffrey R. Stowell. (Feb 2, 2011). Best Practices for Technology-Enhanced Teaching and Learning. Oxford University Press.

7. Mumtaz, S. (2000). Factors Affecting Teachers' Use of Information and Communications Technology: a review of the literature. Journal of Information Technology for Teacher Education, Vol. 9, No. 3.

8. Harris, S., Lowery-Moore, H., \& Farrow, V. . (2008). Extending Transfer of Learning Theory to Transformative Learning Theory: A Model for Promoting Teachers Leadership. Theory into Practice. 47(4), 318-326.

9. Bernard John Poole, John Evans. (2009). EDUCATION FOR AN INFORMATION AGE Teaching In The Computerized Classroom, 7 th edition.

10. Bonnie Swan, Juli Dixon. (2016). The Effects of Mentor-Supported Technology Professional Development on Middle School Mathematics Teachers' Attitudes and Practice. CONTEMPORARY ISSUES IN TECHNOLOGY AND TEACHER EDUCATION.

11. Gary Sykes, Barbara Schneider, David N. Plank. (September 2012). Handbook of Education Policy Research. Routledge for the American Educational Research Association (AERA).

12. Elmer-Dewitt. (1991). Technology and Education Reform: Tecnical Research Report.

13. Riel, M. (Feb, 2014). Educational Change in a Technology-Rich Environment. Journal of Research on Computing in Education, pp. 452-474.

14. Riel, M. (May, 1994). Cross-classroom collaboration in global Learning Circles. The Sociological Review.

15. Olson, N. (2005). Issues of Human Computer Interaction. pp. 192-224.

16. Rodgers, Y., Sharp, H., \& Preece, J. . (2011). Interaction design: Beyond human-computer interaction. Chichester, UK: John Wiley \& Sons Ltd.

17. Brave, S., \& Nass, C. (2002). Emotion in human-computer interaction. In J. Jacko, \& A.Sears (Eds). The human-computer interaction handbook: Fundamentals, evolving technologies and emerging applications.

18. Norman. D. (2002). The design of everyday things. New York: Basic Books.

19. Curtis, B., Kramer, H., and Iscoe, N. (November 1988 ). A field study of the software design process for large systems . Commun. ACM 31, 1268-1287.

20. Gillan, D.J., and Breedin, S. D. (1990). Designers' models of the human-computer interface. In Human Factors in Computing Systems: . Proceedings of SIGCHI'BO (Seattle, Wa, Apr.) (pp. 391-398). New York: ACM.

21. Camerer, C., Loewenstein, G., and Weber, M. . (1989). The curse of knowledge in economic settings: An experimental analysis.” J. Pol.Econ. 97. pp. 1232-1254.

22. Borcnstein, N. (n.d.). The design and evaluation of on-line help systems. Computer Science Depertment. Carnegie Mellon University, Pittsburgh, Pa.

23. Russo, P. and Boor, S. . (1993). How fluent is your interface? Designing for international users. In Human Factors in Computing Systems. Proceedings of INTERCHIP93 (Amsterdam, The Netherkmds, Apr.) (pp. pp. 342-347). New York: ACM.

24. Bailey. (1998). The International Society for Technology in Education (ISTE): "Our Educational System Must Produce Technology Capable Kids" (ISTE, 1998). 